\section{Introducing the star of the backyard}

\section{Simon Mitton}

The Sun, Our Star

By Robert W. Noyes.

Harvard University Press: 1983. Pp.263. $\$ 20, £ 16$.

THE Sun, a run-of-the-mill star, is halfway through its life. Furthermore it is in the middle range of size, temperature and mass for normal stars. Since the next nearest star

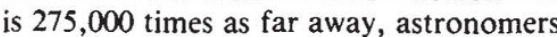
have observed our Sun with a curiosity transcending that for the other stars, all of which are mere specks of light in conventional telescopes. The Sun is the only star where we can study a photosphere, with its attendant sunspots, flares and active regions, on a continuous basis. In recent times spacecraft orbiting the Earth have made detailed measurements in the optical, ultraviolet and X-ray regions in a way that is quite impossible for the other stars.

Professor Robert Noyes is an astrophysicist at Harvard University who has specialized in solar astronomy. His book, an introductory account of solar physics and astronomy, is first-rate. The story opens in a way that will immediately engage the target audience of undergraduates and amateur scientists; we are taken to spend an imaginary day at one of the world's finest solar telescopes, at the Kitt Peak National Observatory, Arizona. The account continues in a straightforward way by describing the physical regimes encountered within and around the Sun. The author keeps hard science in the background; instead of equations and derivations there is good and clear prose, used effectively throughout. Noyes adds interesting historical touches where appropriate, and these lend perspective to the narrative. Solar studies have several times led to important advances in physics, for example the discovery of very highly-ionized atoms and the basic mechanism of energy creation through nuclear fusion.

Recent discoveries treated include the rotation of the core, the invention of solar seismology, the value of Antarctic observatories where the Sun can be watched for days on end, and the solar neutrino problem. The neutrino flux at the Earth is expressed as $3 \times 10^{13}$ neutrinos/sec per reader, which somehow graphically summarizes the difficulty of detecting them. Enduring, but false, stories are laid to rest: no more acoustic heating of the corona - magnetic heating is the answer! The book closes with topical chapters on climate, solar energy and solar evolution. There is no bibliography.

The Sun, Our Star is an excellent introductory account of solar astrophysics and a worthy addition to the long-established Harvard list in astronomy. Just possibly the achievements of space astronomy should have been more closely woven into the main account. The reader waits until the final one-third of the book for much of this (but has been royally entertained meanwhile). Readers outside the United States might also want to quibble with the confusing mixture of units: ${ }^{\circ} \mathrm{C},{ }^{\circ} \mathrm{K}$ and ${ }^{\circ} \mathrm{F}$; meters and miles; cgs and SI; all of these jostle for attention. Diagrams and photographs are plentiful, clear and relevant, and they have the benefit of long, selfexplanatory captions where appropriate. This is a fine book that will stimulate and interest anyone who wishes to have an insight into the scientific knowledge of our very own star.

Simon Mitton, editor of the Cambridge Encyclopaedia of Astronomy, is a science publisher and a Fellow of St Edmund's House, University of Cambridge.

\section{Rocketed to success}

\section{Lee A. DuBridge}

JPL and the American Space Program.

By Clayton R. Koppes.

Yale University Press: 1983. Pp.320.

$\$ 19.95$, f16.95.

THE Jet Propulsion Laboratory is today a huge research and development facility with 4,000 employees, located about six miles from the campus of its parent institution, the California Institute of Technology in Pasadena. It is justly famous for its role in space exploration and for being the first laboratory in the United States to initiate, as early as 1936 , a fundamental study of the science and technology of rocket propulsion. This effort, which initially aimed at very modest goals (e.g. a sounding rocket), led to a 45-year succession of achievements in rocketry, missiles and unmanned space vehicles. Hence the appearance of the first - but (as the author insists) "unofficial" - history of this great institution is a notable event.

JPL also happens to be one of a dozen or so peculiarly American establishments, known as Federally Funded Research and Development Centers (FFRDCs). Each of these is operated by a university, or a consortium of universities, under a contract with a government agency which supplies the funds and the overall direction of its goals and operations. In each case the contract involves a triad of parties: the operating institution, the laboratory itself and the sponsoring agency. It is understandable that many administrative, financial, managerial and even political problems arise in such an arrangement. It is to these "societal" problems that Dr Koppes chooses to give much attention. With extensive documentation, including 32 pages of bibliographical notes, he weaves together the complex story of JPL's ac- tivities and problems. He hopes that the story of one FFRDC might be of interest to others, and will also cast light on the whole area of government-university relations.

This is a worthy aim, but I, personally, feel that Dr Koppes' account is marred by his political-ideological viewpoint, embodied in his assertion that the United States is a "National Security State". By his own definition, this implies that the United States is close to a military dictatorship. But the relations between the government and the American universities during the past 25 years are hardly of the type to be expected under such a regime. The US Space Programme and JPL have been under the auspices of a civilian agency which had no military mission and carried on no secret projects. National "prestige" - to be attained through scientific and technological accomplishment - was certainly a major goal, but this is not the same as "national security".

This reservation apart, Dr Koppes has given us a fascinating account of JPL's history. His story of the early days of JPL is especially interesting, partly because he includes, here and elsewhere, material which has not been previously published. The first studies of rocket propulsion began under the wise and kindly leadership of Theodore von Karman, the distinguished aerodynamicist and Director of the Guggenheim Aeronautical Laboratories of the California Institute of Technology (GALCIT). His associates were a few graduate students and enthusiastic volunteers, led by a perceptive and sensitive student named Frank Malina. Having heard of earlier rocket experiments, particularly those of Robert H. Goddard of Clark University, this group was anxious to proceed with rocket research. Karman cautioned them, however, that first they must gain a thorough understanding of the basic theory of rocket combustion and propulsion. Then they should make wellinstrumented static tests and, only after that, should they try flight testing. By following this procedure over the years, GALCIT, and shortly afterwards the JPL, became, in Koppes' words, "the seed bed of American rocketry". However, the GALCIT project might well have remained both struggling (for funds and manpower) and small, had it not been for a series of national and world events which radically changed its course.

First came the Munich crisis of 1938 , which shocked the US military leadership into action. General H. H. Arnold, Chief of the US Army Air Corps, who had seen the GALCIT experiments, offered a "huge" grant of $\$ 10,000$ to finance the development of JATO (Jet Assisted Takeoff) rockets for aircraft. More funds soon followed, and JPL itself now "took off" on the first of its series of major development programmes. Important advances in the technology of both liquid- and solidpropellant rockets resulted in JATO's ultimate success. 
The 1943 reports of the German rocket activity led the US Army Ordnance Department to enter into a contract with Caltech for the continued operation of JPL, under which JPL would develop artillery-type ballistic missiles. This effort continued into the Cold War period, and from it emerged the Corporal E liquid-propellant missile and the Sergeant solid-propellant weapon, both of which were eventually deployed in Europe. The latter was the forerunner of the modern Pershing missiles. The anxiety of the government to get these weapons into production as quickly as possible caused much confusion and frustration at JPL. Yet in this period the laboratory learned much about system analysis and development, and also took the first, crucial steps towards creating what ultimately became a spectacularly successful system of electronic guidance, control and communication for missiles and spacecraft.

This missile research was terminated with the appearance of Sputnik and the initiation, in 1958, of the US space programme, managed by a new civilian agency, the National Aeronautics and Space Administration (NASA), which took over the JPL contract. Caltech and JPL were glad to close their secret military weapons programme and to engage in a more scientifically rewarding enterprise. Spectacular managerial problems among the administrators within the Caltech-JPL-NASA triangle, all of which are fully described by Dr Koppes. This was the era, however, in which the appellation "National Security State" seems to have the least relevance, even though the Caltech-JPL-NASA relations were at their most difficult. The problems stemmed, not from security considerations, but from the policy of NASA to monitor most critically every aspect of the performance of JPL, at a time when that establishment was tackling the most challenging problems in its history.

It was ironic that just when Viking and Voyager projects brought JPL to the peak of its prestige, the government began to cut back on planetary exploration, partly because the Space Shuttle programme was soaking up such a large proportion of the NASA budget. JPL suffered serious setbacks when the US portion of the International Solar Polar mission was cancelled, as well as the proposed fly-by to Halley's comet. The only new project remaining for JPL is the Galileo mission to Jupiter, carrying a probe to be released into Jupiter's atmosphere.

Galileo, the future space telescope and other scientific instruments are to be carried on the Space Shuttle, along with a variety of secret military payloads. This im-

\section{Schemes and dreams of fusion}

\author{
Philip Davenport
}

Fusion: Science, Politics, and the

Invention of a New Energy Source.

By Jean Lisa Bromberg.

MIT Press: 1982. Pp.343. \$30, £24

CONTROLLED thermonuclear research (CTR) has as its primary goal the demonstration that nuclear fusion reactions between light elements can provide us with a new and benign energy source. But despite over 30 years of steadily expanding endeavour by many countries, now freely collaborating, this goal still eludes us. Opening the first International Conference on the Peaceful Uses of Atomic Energy in 1955 , when the subject was still classified as secret by the nuclear powers, Homi J. Bhabha of India predicted, "a method will be found for liberating fusion energy in a controlled manner within the next two decades". Much the same might be said today.

This situation, though favourable for the job prospects of plasma physicists, puts the historian in a quandary; any account of a national fusion programme must necessarily be open-ended - should one wait for a successful outcome to round it off neatly? The answer is an actuarial no; several pioneers of fusion have already died - Thomson, Cockcroft and Chick in Britain, Kurchatov, Sinelnikov and Artsimovich in Russia, and Ruark, Christofilos and Tuck in the United States. (Fortunately Dr Bromberg started her work in good time to interview Tuck.) Others candidly admit to having memories that are dulled or, more embarrassing, inventive; the historian has little time to spare.

As the subtitle of her book suggests, Joan Bromberg has concentrated on the political and organizational aspects of the Magnetic Fusion Program in the United States, while providing just the right amount of scientific background and detail to enable the non-specialist reader to understand the principles of the various experimental approaches described. The result is a fascinating account of how the development of one governmentsponsored research project has been shaped by scientists, politicians, industrialists and world events.

Experimental work on CTR began quietly in Britain in the late 1940s, with a total of about a dozen scientists working in three small groups at the universities of Oxford, London and Liverpool. Although this work received no publicity, quite a few physicists knew about it; significantly, these included James Tuck, working at Oxford, and Klaus Fuchs at Harwell. Tuck moved to the United States in 1949, became naturalized, and initiated the fusion programme at Los Alamos which later became 